Syntax Fusion: Jurnal Nasional Indonesia

e-ISSN: 2775-4440

Vol. 1, No. 10, Oktober 2021

\title{
PENYEBAB DAN GEJALA YANG TIMBUL DARI PENYAKIT NEURALGIA TRIGEMINAL
}

\author{
Dinda Rifdayani Inayah, Baiq Ananda Audia Arsiazi, Baiq Risha Feby Amelia, Nur \\ Fadlia Rahmani, Noer Aulya Amy Aprilia
}

Universitas Mataram, Indonesia.

Email: rifdayani13@gmail.com baiqfeby3@gmail.com,nanda18audia@gmail.com, nurfadlia2519@gmail.com,noeraulyaamyaprilia99@gmail.com

\begin{abstract}
Abstrak
Defisit somatosensori yang diakibatkan oleh perubahan jalur somatosensori dapat mengakibatkan kelainan yaitu nyeri. Saraf trigeminal merupakan saraf kranial V yang berperan dalam persarafan sensorik dan motorik wajah, dimana informasi sensoriknya adalah sentuhan, nyeri dan suhu. Penulisan artikel ini mencakup berbagai sumber dari jurnal ilmiah serta pedoman dari pemerintah dan instansi terkait. Neuralgia trigeminal atau tic douloureux adalah penyakit yang terjadi akibat kelainan pada saraf kranial $V$ dengan gejala nyeri wajah yang tiba-tiba, unilateral, kronis, jangka pendek, menusuk, berulang diikuti dengan kontraksi wajah. Insiden neuralgia trigeminal $90 \%$ terjadi pada usia 40, sedangkan prevalensi populasi adalah 4,3 per 100.000 penduduk, rasio wanita-pria adalah 1,74: 1, dan lebih sering terjadi pada wajah kanan daripada kiri. 1. Pengobatan neuralgia trigeminal bersifat non-medis dan medis, tetapi pembedahan harus dipertimbangkan jika pengobatan kurang efektif atau dapat ditoleransi. Hiperaktivitas disfungsional trigeminal dapat menyebabkan neuralgia trigeminal dan dapat dicegah dengan menghindari pemicu nyeri. Gejalanya meliputi episode nyeri berulang yang satu sisi, tiba-tiba, parah, berumur pendek, menusuk, kronis, dan sering disertai dengan kejang wajah setelah kerusakan sensorik saraf trigeminal.
\end{abstract}

Kata Kunci: Nervus Trigeminal; Trigeminal Neuralgia; Kesehatan.

Diterima: 19-09-2021 Direvisi: 15-10-2021 Disetujui: 18-10-2021

\section{Pendahuluan}

Defisit somatosensori yang dihasilkan dari lesi di sepanjang jalur somatosensori termasuk lesi kortikal dan subkortikal yang dapat menyebabkan parestesia dan mati rasa pada ekstremitas kontralateral. Semua jalur sensorik di bawah talamus yang dapat menyebabkan hilangnya sensasi tubuh pada sisi yang berlawanan. Di batang otak, mencakup semua jalur kecuali rasa sakit dan suhu yang dapat menyebabkan parestesia kontralateral pada wajah dan 
Dinda Rifdayani Inayah, Baiq Ananda Audia Arsiazi, Baiq Risha Feby Amelia, Nur Fadlia Rahmani, Noer Aulya Amy Aprilia

tubuh, kerusakan pada segmen trigeminal dan tulang belakang-talamus lateral yang dapat mengganggu persepsi nyeri, suhu wajah dan tubuh di sisi lain.

Kerusakan pada lemniskus medial dan segmen anterior segmen spinal-thalamic yang dapat merusak semua modalitas sensorik pada sisi tubuh yang berlawanan kecuali nyeri dan suhu, serta nukleus spinalis dan segmen NV dan segmen spinothalamic lateral, yang dapat mempengaruhi persepsi rasa sakit dan suhu di bagian wajah yang sama dan bagian tubuh yang berlawanan. Cedera pilar posterior yang dapat menyebabkan hilangnya sensasi posisi dan getaran, diskriminasi dan ataksia pada sisi yang sama, kornu posterior medula spinalis dapat menyebabkan hilangnya sensasi nyeri dan suhu ipsilateral, radiks posterior multipel yang berdekatan dapat menyebabkan nyeri radikuler, hipotensi, atau atonia (Baehr \& Fritscher, 2011).

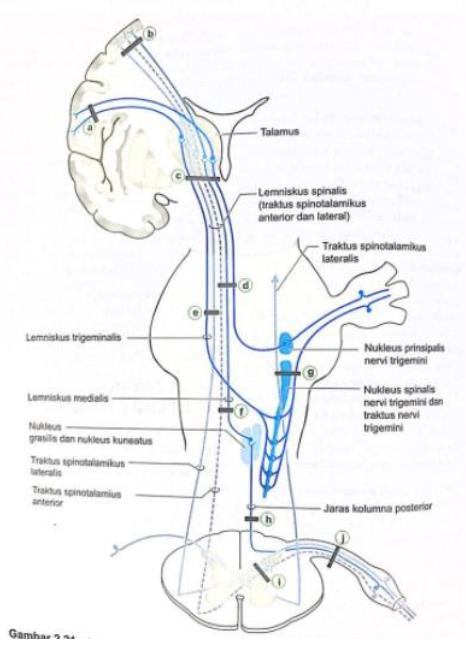

(Baehr \& Fritscher, 2011).

Saraf trigeminus merupakan saraf kranial V yang berperan dalam menyampaikan persarafan sensorik dan motorik wajah, dimana informasi sensorik yang diberikan meliputi sentuhan, nyeri, dan suhu (Daly dan Huff, 2020). Informasi sensorik ini ditransmisikan melalui nukleus trigeminal dan thalamic sebelum mencapai korteks serebral dan sinapsis di gyrus postcentral. Salah satu nyeri neuropatik yang paling umum di daerah kraniofasial adalah neuralgia trigeminal, atau juga dikenal sebagai douloureux tic (Veerapaneni et al., 2021). Akar saraf sensorik dan motorik saraf trigeminal muncul dari jembatan medial lateral, di mana akar saraf motorik (portio minor nervi trigemini) lebih kecil dari akar saraf sensorik (portio mayor nervi trigemini). Akar saraf sensorik ini terus menjadi ganglion Gasseri dan terbagi menjadi 3 cabang yaitu saraf optik, saraf maksilaris, dan saraf mandibula (Dina dan Gunawan, 2018). 

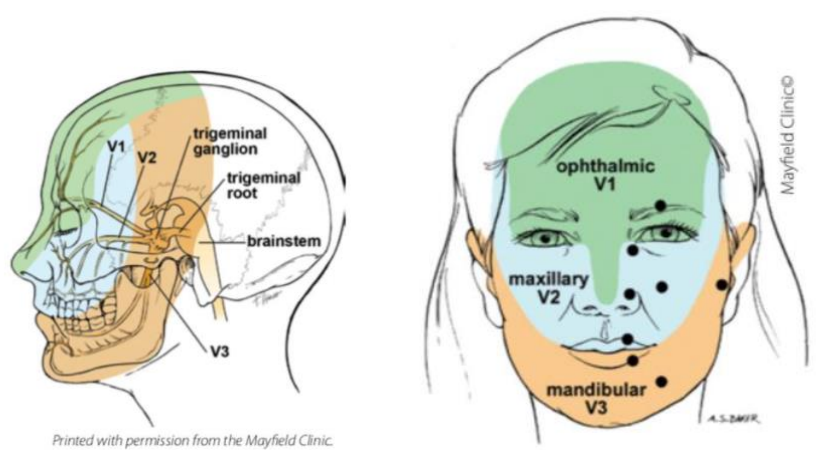

(Baehr \& Fritscher, 2011)

Neuralgia trigeminal adalah episode nyeri berulang yang bersifat sepihak, tiba-tiba, berat, berumur pendek, menusuk, kronis, dan sering disertai spasme wajah yang berhubungan dengan distribusi sensorik saraf trigeminal (Zakrzewska dan Mc Millan, 2011). Insiden neuralgia trigeminal adalah $90 \%$ pada orang di atas usia 40, dengan insiden tertinggi terjadi antara usia 60 dan 70. Berdasarkan jumlah penduduk, prevalensinya adalah 4,3 per 100.000 penduduk, rasio perempuan terhadap laki-laki adalah 1,74:1, dan lebih sering terjadi pada wajah sebelah kanan daripada di sebelah kiri dengan perbandingan 1,5:1 (Dina \& Gunawan, 2018).

Penyebab neuralgia trigeminal adalah multifaktorial, dengan penyebab paling umum adalah idiopatik. Selain itu, mungkin karena kompresi vaskular saraf trigeminal, multiple sclerosis, tumor kompresi saraf, penebalan arachnoid fokal, adhesi, traksi, dan aneurisma (Veerapaneni et al., 2021). Faktor risiko neuralgia trigeminal antara lain jenis kelamin perempuan, usia di atas 40 tahun, hipertensi arteri, riwayat aterosklerosis, dan riwayat keluarga trigeminal neuralgia (Duransoy et al, 2013).

Tatalaksana yang dapat diberikan pada pasien neuralgia trigeminal dapat berupa terapi medikamentosa dan nonmedikamentosa, dimana farmakoterapi diberikan terlebih dahulu dibanding terapi invasif lainnya. Terapi non medikamentosa yang dapat diberikan berupa edukasi kepada pasien untuk menghindari faktor pencetus nyeri (seperti mencuci muka, menggosok gigi, mencukur, mengaplikasikan make up, serta getaran saat berjalan), proses perjalanan penyakit dan efek samping obat-obatan yang akan diberikan (Zakrzewska dan Mc Millan, 2011).

\section{Metode Penelitian}

Pada penulisan artikel ini mencakup berbagai sumber yang berasal dari jurnal ilmiah dan pedoman pemerintah maupun instansi terkait. Pencarian sumber dilakukan di portal online publikasi jurnal seperti MedScape, Google Scholar (scholar.google.com) dan National Center for Biotechnology Information/NCBI (ncbi.nlm.nih.gov), dengan kata kunci yang digunakan adalah "Sensoric Nerve Trauma". 
Dinda Rifdayani Inayah, Baiq Ananda Audia Arsiazi, Baiq Risha Feby Amelia, Nur Fadlia Rahmani, Noer Aulya Amy Aprilia

\section{Hasil dan Pembahasan}

Neuralgia trigeminal adalah episode nyeri berulang yang bersifat unilateral, mendadak, berat, berumur pendek, menusuk, kronis, dan sering disertai spasme wajah yang berhubungan dengan distribusi sensorik nervus trigeminal (Dina dan Gunawan, 2018).

Berdasarkan penyebabnya, nyeri trigeminal tidak dapat dijelaskan secara pasti. Namun, beberapa tes, seperti MRI, menunjukkan tekanan atau kompresi akar saraf trigeminal dan pembuluh darah di sekitarnya. Hal ini juga dapat menyebabkan rasa sakit di sekitar wajah pasien dan dapat berlangsung dalam waktu yang lama. Oleh karena itu, penelitian klinis tentang nyeri yang dialami pasien perlu diperdalam dalam diagnosis nyeri (Nurmikko dan Eldridge, 2001). Adapun yang mencantumkan penyebab nyeri ini karena adanya cedera pada saraf trigeminal dan adanya demielinasi. Sensasi nyeri dapat dirasakan di satu bagian wajah atau di satu sisi, atau kaku di satu sisi wajah (Gillig dan Sanders, 2010).

\section{A. Faktor Resiko}

Neuralgia trigeminal adalah suatu sindrom yang disebabkan oleh hiperaktivitas disfungsional saraf trigeminal, nyerinya akut dan gejalanya muncul tiba-tiba, biasanya unilateral, dan dapat terjadi berulang kali pada satu atau lebih cabang saraf. Insiden neuralgia trigeminal berkisar 4,5 per 100.000 orang. Hal ini paling sering terjadi pada wanita dibandingkan pada pria. Rasionya kira-kira 1,74:1. Dan juga paling sering antara usia 50 dan 69 tahun. Hipertensi, aterosklerosis, penuaan, sensitivitas, riwayat keluarga, dan ras juga merupakan faktor risiko penting untuk neuralgia trigeminal. Transmisi genetik neuralgia trigeminal juga telah dilaporkan, dan pewarisan dominan autosomal ditemukan pada 1-2\% kasus. Juga telah ditemukan bahwa stres dan faktor emosional juga dapat memicu berbagai bentuk neuralgia. Nyeri yang terkait dengan neuralgia trigeminal paling sering disebabkan oleh kompresi yang disebabkan oleh pembuluh darah trigeminal yang memiliki zona transmisi ke batang otak..

\section{B. Manifestasi Klinis}

Dari segi gejala, neuralgia trigeminal dapat dibagi menjadi 2 jenis, yaitu neuralgia trigeminal tipe 1 (TN1) dan tipe 2 (TN2). Type 1 hanya ada nyeri paroksismal. Umumnya dikenal sebagai tic douloureux dan nyeri wajah dengan onset spontan lebih dari 50\%, TN1 biasanya disebabkan oleh hilangnya atau kerusakan lapisan saraf pelindung (myelin). Kerusakan mielin terjadi karena iritasi pada saraf, biasanya darah di pembuluh darah, yang menyebabkan saraf terkompresi.

Sedangkan Neuralgia trigeminal tipe 2 (TN2) nyeri paroksismal yang tiba-tiba dan persisten. Biasanya ada juga nyeri wajah spontan dengan lebih dari $50 \%$ nyeri konstan. Neuralgia trigeminal sekunder (TNS) adalah timbulnya rasa sakit dari penyebab atau kondisi lain, seperti tumor atau multiple sclerosis. Post Herpetic Neuralgia (PHN) adalah nyeri yang disebabkan oleh herpes zoster di sepanjang saraf trigeminal.

Nyeri trigeminal neuropathy $(\mathrm{PAH})$, nyeri wajah akibat cedera pada cabang saraf trigeminal di sekitar wajah, efek pasca operasi bedah mulut dan THT, trauma bagian 
belakang tengkorak akibat operasi, stroke, dan lain-lain. Nyeri ini digambarkan sebagai sensasi tumpul, terbakar, dan terkadang spontan dan konstan yang disebabkan oleh penyebaran impuls dari otak. Sensasi nyeri ini juga dapat dirangsang karena adanya reaksi hipersensitivitas, sehingga serangannya bersifat akut. Beberapa area sensitif untuk disentuh juga akan menjadi lebih sensitif karena rasa sakit ini. Kekakuan dan ketidaknyamanan wajah juga bisa menjadi tanda gangguan saraf.

Nyeri pada neuralgia trigeminal bersifat paroksismal dan biasanya tiba-tiba, kadang disertai nyeri hebat, dan terlihat spasme otot wajah. Biasanya, pasien dengan neuralgia trigeminal sendiri menggambarkan rasa sakit yang mirip dengan sengatan listrik, yang berlangsung dari satu hingga beberapa detik. Nyeri TN biasanya satu sisi tetapi kadangkadang bilateral, tetapi jarang terjadi secara bersamaan di kedua sisi. Dan rasa sakit ini jarang terjadi saat tidur.

Cabang V1 dan V2 dari saraf trigeminal biasanya disertai dengan rasa sakit, dan jika V1 terpengaruh, gejala otonom ringan seperti lakrimasi, rinore dan konjungtiva dapat diamati. Namun, percabangan V1 yang terisolasi dan jarang kadang terlihat pada kurang dari $5 \%$ pasien dengan neuralgia trigeminal.

\section{Patofisiologi}

Patofisiologi dari kondisi ini masih belum dipahami dengan sempurna. neuralgia trigeminal terjadi karena kompresi pada akar saraf trigeminal oleh pembuluh darah, biasanya arteria cerebelar superior, melingkar di sekitar bagian proksimal, bagian tak bermielin dari akar saraf segera setelah keluar dari pons.

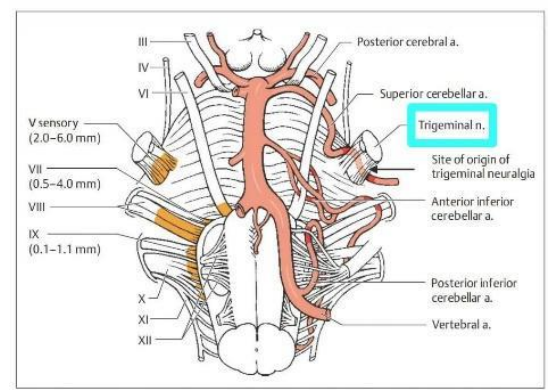

(Baehr \& Fritscher, 2011)

Hal ini didukung dengan pengamatan pada $80 \%$ pasien yang telah mengalami prosedur bedah untuk mengurangi rasa sakit yang dirasa dengan memisahkan bagian saraf trigeminal dan pembuluh darah. Rasa sakit dapat berkurang secara signifikan, atau bahkan dieliminasi, pada 80-90\% kasus dengan terapi seperti penggunaan carbamazepine, gabapentin and pregabalin. Intervensi bedah saraf diindikasikan hanya jika nyeri terjadi berulang bahkan setelah terapi pengobatan. Pilihan untuk perawatan bedah saraf termasuk dekompresi mikrovaskuler dan termoregulasi perkutan selektif dari nosiseptor serabut saraf trigeminal. 
Dinda Rifdayani Inayah, Baiq Ananda Audia Arsiazi, Baiq Risha Feby Amelia, Nur Fadlia Rahmani, Noer Aulya Amy Aprilia

Penyebab paling umum dari gejala neuralgia trigeminal adalah sklerosis multipel: 2,4\% dari semua pasien MS mengembangkan neuralgia trigeminal; antara pasien ini, 14\% memilikinya secara bilateral. Penyebab nyeri simptomatik lainnya yang lebih jarang di distribusi saraf trigeminal termasuk gigi lesi, sinusitis, patah tulang, dan tumor pada sudut cerebellopontine, hidung, atau mulut. Nyeri pada mata atau dahi juga harus menimbulkan kecurigaan terhadap glaukoma atau iritis. Nyeri glaukoma akut bisa menyerupai neuralgia trigeminal klasik.

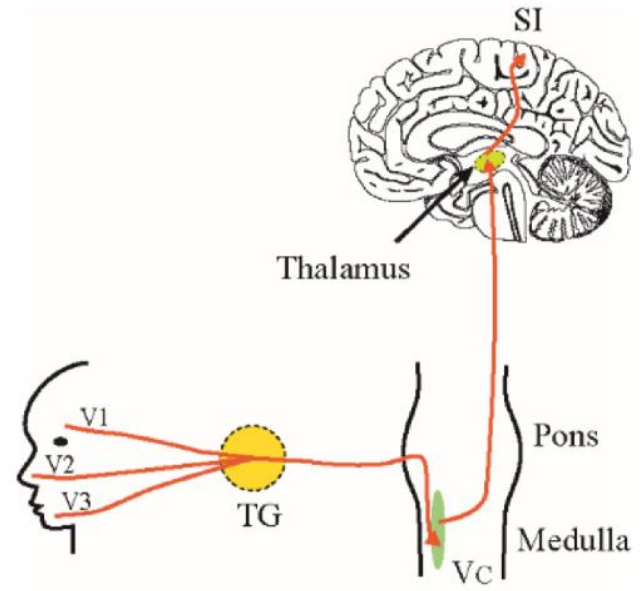

Gambar Penjalaran impuls nervus trigeminal.

Sinyal ditransmisikan secara terpusat melalui serat aferen ini ke nucleus trigeminal spinal caudalis (Vc) dari inti batang otak di mana mereka bersinaps dengan neuron orde dua yang memproyeksikan ke korteks somatosensorik dan limbik melalui talamus (Gambar 2). Sepanjang jalur menaik ini, informasi berbahaya dimodulasi oleh jalur modulasi nyeri lokal dan menurun yang menghambat atau memfasilitasi informasi sensorik yang ditransmisikan. Input turun ke Vc berasal dari korteks somatosensorik primer (SI), korteks somatosensori sekunder (SII), insula dan dari Rostral Ventromedial Medulla (RVM). Adapun pengaruh dari faktor psikologis seperti emosi, dan keadaan pikiran seperti perhatian, pemahaman, kontrol, harapan, dan signifikansi permusuhan dapat mengubah persepsi rasa sakit di antara individu. Oleh karena itu, nyeri dipersepsikan sebagai interaksi dinamis dari unsur kognitif, afektif dan sensorik sehingga menjadi sensasi subjektif (Bista \& Imlach, 2019).

\section{Tatalaksana}

Tatalaksana pada trigeminal neuropathy terdapat non medikamentosa dan medikamentosa, namun jika terdapat penurunan keefektifan atau tolerabilitas pada pengobatan, pembedahan perlu dipertimbangkan. Terapi non-medikamentosa yang pertama yaitu edukasi. Edukasi pasien untuk menghindari maneuver yang memicu rasa nyeri dan edukasi mengenai perjalanan penyakit. Penting juga untuk edukasi mengenai efek samping obat terutama antikonvulsan yang dapat menyebabkan ataksia, sedasi dan mempengaruhi 
fungsi hati, serta edukasi pasien untuk mengetahui gejala-gejala dari efek samping obat (Gunawan \& Dina, 2019).

Farmakoterapi harus dimulai paling dulu sebelum terapi invasif lainnya. Menurut European Federation of Neurological Societies and the Quality Standards Subcommittee of the American Academy of Neurology mempertimbangkan karbamazepin sebagai obat pilihan untuk trigeminal neuropathy. Food and Drug Administration (FDA) juga menyetujui penggunaan karbamazepin pada pasien trigeminal neuralgia. Cara kerja karbamazepin yaitu dengan menghambat aktivitas saluran natrium dan modulasi saluran kalsium. Pada beberapa penelitian karbamazepin memberikan pengendalian nyeri yang tinggi. Dosis awal yang sering digunakan yaitu 100 hingga $200 \mathrm{mg}$ dua kali sehari dan meningkat secara bertahap menjadi 200mg. Efek samping penggunaan karbamazepin yaitu mengantuk, pusing dan mual. Efek samping yang parah bisa terjadi anemia aplastic, hyponatremia, dan tes fungsi hati yang abnormal. Beberapa pasien yang tidak dapat mentolerir karbamazepin dosis tinggi dapat mengonsumsi antikonvulsan (Yadav et al., 2017).

Obat lini kedua trigeminal neuralgia yaitu lamotrigine 100-400 mg/hari yang bekerja menghambat voltage-gated sodium channel yang akan menstruasi membran neural dan baclofen $60-80 \mathrm{mg} /$ hari yang bekerja dengan memfasilitasi inhibisi segmental pada kompleks trigeminal. Penggunaan okskarbazepin dapat digunakan sebagai pengganti apabila karbamazepin tidak bisa ditoleransi, karena efek samping yang lebih sedikit. Dosis oxcarbazepine 300-2400 mg/hari. Okskarbazepin bekerja dengan memblokir voltage-gated sodium channel dan memodulasi voltage-gated calcium channel. Efek samping yang mungkin terjadi adalah dizziness dan gangguan memori (Gunawan \& Dina, 2018).

Radiosurgery gamma knife merupakan suatu prosedur yang menargetkan zona akar masuk trigeminal di fossa posterior dan bertujuan untuk memfokuskan sinar radiasi (Zakrzewska \& McMillan, 2011). Radiasi dapat menghalangi konduksi informasi sensorik yang berlebihan. Radiosurgery terutama mempengaruhi selubung mielin. Jika pengobatan menggunakan mikrovaskular dekompresi (MVD) gagal, direkomendasikan menggunakan radiosurgery gamma knife dengan indikasi trigeminal neuropathy tipikal atau atipikal dengan atau tanpa kompresi vascular. Penggunaan dosis tinggi dapat mengontrol nyeri yang lebih baik dan meminimalisir kekambuhan, namun memiliki efek samping seperti mati rasa pada wajah. Maka dari itu, informed consent pada pasien sangat diperlukan sebelum Tindakan tersebut.

Kompresi balon perkutan selektif menghindari cedera pada serat kecil yang tidak bermielin yang memediasi refleks kornea dan merupakan metode yang aman, sederhana dan efektif untuk menghilangkan rasa sakit sementara sekitar 90\%. Kompresi balon perkutan diindikasikan pada pasien yang sulit berkomunikasi dan untuk pasien yang terkena efek glycerol rhizotomy. Prosedur dapat dilakukan dengan bius lokal atau total dengan waktu 6090 detik, beberapa penelitian mengatakan waktu kompresi yang lebih lama menghasilkan hasil yang lebih baik. Bentuk balon seperti pir merupakan indikasi kompresi yang tepat dan 
Dinda Rifdayani Inayah, Baiq Ananda Audia Arsiazi, Baiq Risha Feby Amelia, Nur Fadlia Rahmani, Noer Aulya Amy Aprilia

meminimalisir rasa sakit, sedangkan berbentuk elips yang persisten adalah pertanda buruk dan indikasi untuk membatalkan prosedur. Kegagalan teknis pada tindakan ini sebesar $2 \%$.

Glycerol Rhizotomy (GR) diindikasikan untuk pasien yang tidak responsif terhadap obat-obatan, signifikan komorbiditas medis, multiple sclerosis (MS), unilateral dan bilateral dan gagal setelah dilakukan mikrovaskular dekompresi. Suntikan perkutan dapat meredakan nyeri selama beberapa bulan hingga tahun (Majeed et al., 2018). Biaya GR lebih hemat dibandingkan MVC, radiofrequency thermocoagulation (RFTC), dan kompresi balon perkutan. GR juga aman dan efektif jika dilakukan berulang dengan komplikasi yang dapat disembuhkan. Tingkat keberhasilan GR sekitar 95\% dengan 50\%-60\% kekambuhan pada 24 bulan tindak lanjut.

Radiofrequency Thermocoagulation RFTC bisa digunakan dalam patologi bilateral, pasien usia lanjut, kambuh setelah gagal MVD, vertebrobasilar dolichoectasia dan MS. Blok saraf tepi dan anestesi umum dapat meredakan nyeri perioperative tanpa peningkatan komplikasi.

Peripheral Nerve Section peripheral neurectomy merupakan Tindakan yang aman dan memiliki prosedur yang efektif untuk pasien usia lanjut, dan pada pelayanan kesehatan yang tidak memiliki fasilitas bedah saraf. Neurektomi segmen fossa pterygopalatina pada saraf maksilaris dapat digunakan pada lansia yang mungkin tidak dapat mentoleransi kraniotomi, atau bila pengobatan RFTC dan GR tidak memungkinkan. Pereda nyeri dapat berlangsung 15 hingga 24 bulan. Kehilangan sensasi dan kekambuhan berhubungan dengan neurektomi perifer.

Partial Sensory Root Section (PSRS) PSRS diindikasikan pada MS terkait dengan eksplorasi pembuluh darah negatif selama MVD dan vena intra neural yang besar sulit untuk dimobilisasi. PSRS juga direkomendasikan dalam eksplorasi ulang setelah MVD gagal saat tidak ada neurovascular compression (NVC). Hasil yang sangat baik diamati pada $70 \%$ kasus dengan gangguan sensorik minimal.

Microvascular Decompression (MVD) MVD diindikasikan untuk TN tipe 1 maupun tipe 2 dengan NVC. MVD merupakan perawatan bedah yang tidak destruktif atau ablatif karena tidak bertujuan hanya untuk mengurangi masukan sensorik dimana dapat menimbulkan kerusakan saraf melainkan bertujuan untuk menjaga fungsi saraf trigeminal (Zakrzewska \& McMillan, 2011).

MVD dilakukan dengan anestesi umum menggunakan mikroskop untuk mengidentifikasi saraf trigeminal. Arteri atau vena yang menyebabkan tekanan pada saraf trigeminal diangkat atau diubah posisinya untuk meredakan kompresi. Prosedur ini dilakukan secara endoskopi (Majeed et al., 2018). 


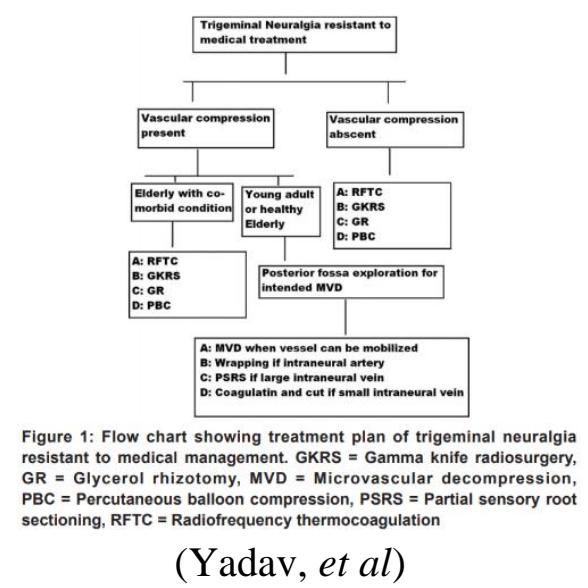

\section{E. Pencegahan}

Mencegah trigeminal neuralgia tidak memiliki pedoman khusus untuk mencegah trigeminal neuralgia, namun ada beberapa hal yang dapat dilakukan, seperti mengonsumsi makanan lunak, menghindari makanan yang terlalu panas atau terlalu dingin, mencuci muka dengan air hangat, dan menggunakan kapas, dan yang paling penting adalah menghindari faktor risiko pemicu nyeri. Neuralgia trigeminal lebih sering terjadi pada usia 40-an, jadi perhatikan baik-baik orang-orang di sekitar Anda untuk menghindari hal-hal yang tidak diinginkan seperti jatuh dan cedera kepala yang dapat menyebabkan neuralgia trigeminal. (Singh, 2019).

\section{Kesimpulan}

Neuralgia trigeminal adalah sindrom yang dihasilkan dari aktivitas berlebihan disfungsional dari saraf trigeminal. Gejalanya meliputi episode nyeri berulang yang satu sisi, tiba-tiba, parah, berumur pendek, menusuk, kronis, dan sering disertai dengan kejang wajah setelah kerusakan sensorik saraf trigeminal. Penyebab paling umum adalah idiopatik dan dapat disebabkan oleh kompresi vaskuler saraf trigeminal, multiple sclerosis, tumor kompresi saraf, penebalan fokal arachnoid, adhesi, traksi, dan aneurisma. Faktor risiko termasuk jenis kelamin perempuan, usia di atas 40 tahun, hipertensi, sensitivitas, dan aterosklerosis. Penatalaksanaan yang diterapkan berupa terapi terapeutik yang terdiri dari pemberian karbamazepin dan lamotrigine, serta terapi non medis berupa edukasi yang ditujukan untuk menghindari faktor penyebab nyeri, perjalanan penyakit dan efek samping obat. 
Dinda Rifdayani Inayah, Baiq Ananda Audia Arsiazi, Baiq Risha Feby Amelia, Nur Fadlia Rahmani, Noer Aulya Amy Aprilia

\section{BIBLIOGRAFI}

Bista, P dan Imlach, W. L. 2019. Pathological Mechanism and Therapeutic Targets for Trigeminal Neuropathic Pain. Department of Physiology \& Monash Biomedicine Discovery Institute, Monash University, Melbourne, Australia. Google Scholar.

Baehr, M dan Fritscher, M. 2011. Duus' Topical Diagnosis in Neurology Anatomy, Physiology, Signs, Symptoms. [p. 107-108] Google Scholar.

Dina A, Gunawan P. 2018. Trigeminal Neuralgia, Etiologi, Patofisiologi, dan Tatalaksana. Google Scholar.

Duransoy Y, dkk. 2013. Differences in individual susceptibility affect the development of trigeminal neuralgia. Vol 8. Google Scholar.

Gillig, P. M dan Sanders, R. D. 2010. THE TRIGEMINAL (V) AND FACIAL (VII) CRANIAL NERVES: Head and Face Sensation and Movement. Departments of Psychiatry and Neurology, Boonshoft School of Medicine, Wright State University, and Ohio VA Medical Center, Dayton, Ohio. Vol. 7 no. 1. [p. 25-26] Google Scholar.

Huff T, Daly DT. 2020. Neuroanatomi, Saraf Cranial 5 (Trigeminal). StatPearls. Google Scholar.

Nurmikko, T. J dan Eldridge, P. R. 2001. Trigeminal neuralgia--pathophysiology, diagnosis and current treatment. British Journal of Anesthesia. [p. 120-121] Google Scholar.

Singh, M., 2019. Trigeminal Neuralgia: Practice Essentials, Background, Anatomy. [online] Emedicine.medscape.com. Google Scholar.

Veerapaneni KD, N Kapoor, Veerapaneni P, dkk. Neuropati Trigeminal: StatPearls. Google Scholar.

Yadav, et al. 2017. Trigeminal Neuralgia. Asian Journal of Neurosurgery. Vol 12. (4). Google Scholar.

Zakrzewska J, Mc Millan R. 2011. Trigeminal neuralgia: the diagnosis and management of this excruciating and poorly understood facial pain. Vol 87. Google Scholar. 